\title{
FRANCIS GOYET, Le Regard rhétorique
}

\section{Maurizio Busca}

\section{(2) OpenEdition \\ Journals}

\section{Édition électronique}

URL : https://journals.openedition.org/studifrancesi/31493

DOI : 10.4000/studifrancesi.31493

ISSN : 2421-5856

\section{Éditeur}

Rosenberg \& Sellier

\section{Édition imprimée}

Date de publication : 1 août 2020

Pagination : 387-388

ISSN : 0039-2944

\section{Référence électronique}

Maurizio Busca, « FRANCIS goyet, Le Regard rhétorique », Studi Francesi [En ligne], 191 (LXIV | II) | 2020, mis en ligne le 01 septembre 2020, consulté le 16 septembre 2021. URL : http://

journals.openedition.org/studifrancesi/31493; DOI : https://doi.org/10.4000/studifrancesi.31493

Ce document a été généré automatiquement le 16 septembre 2021.

\section{(c)}

Studi Francesi è distribuita con Licenza Creative Commons Attribuzione - Non commerciale - Non opere derivate 4.0 Internazionale. 


\title{
FRANCIS GOYET, Le Regard rhétorique
}

\author{
Maurizio Busca
}

\section{RÉFÉRENCE}

FRANCIS GOYET, Le Regard rhétorique, Paris, Classiques Garnier, 2017, «L'univers

rhétorique» 4, $408 \mathrm{pp}$.

1 «Qu'avons-nous perdu au juste en perdant l'immense culture de la rhétorique ancienne?» è la domanda con cui si apre il presente saggio. La risposta che propone l'A., tracciando un bilancio di ricerche trentennali sulla storia della retorica nell'età moderna, è la seguente: si è perso «un certain type de regard»; più precisamente, si è perso un certo tipo di educazione volta a coltivare la capacità di riconoscere e apprezzare la struttura d'insieme di un discorso (totum) e non soltanto, o non principalmente, le singole parti che lo costituiscono (omnia). I dieci capitoli che compongono il volume, frutto della rielaborazione di undici studi pubblicati nel corso degli ultimi vent'anni, affrontano la questione della dialettica fra il totum e gli omnia di opere letterarie e teatrali, orazioni giudiziarie, testi critici e teorici dei secoli XVI-XVIII, con puntuali escursioni in testi dell'Antichità.

2 Le analisi sono organizzate in una struttura tripartita. La prima parte (“'Voir’ le personnage comme un tout») è introdotta da un denso capitolo di carattere teorico dedicato alle considerazioni formulate in epoca classica, segnatamente da Cicerone e da Quintiliano, sulle definizioni di ipotiposi e di evidentia e sul problema della «visibilité éclatante du 'type'» come possibilità di accesso alla dimensione dell'invisibile («De l'hypotypose au 'type'. L'evidentia est et n'est pas visuelle», pp. 31-70). Gli strumenti critici definiti in queste prime pagine sono applicati, nei tre capitoli seguenti, allo studio dei processi di costruzione dei personaggi di testi tragici, epici e lirici («Voir avec les yeux de la pitié. Athalie et Joas», pp. 71-108; «Voir le tout du tout. L'orateur Drancès dans l'économie de l'Énéide», pp. 109-146; «Désintégrations. L'échec d'Hamlet n'est pas celui de la rhétorique», pp. 147-172). Nella seconda parte del volume, intitolata «Voir la stratégie d'un discours. Les plaidoiries», è preso in esame il campo 
dell'oratoria giudiziaria. Dopo un primo capitolo volto a illustrare la struttura e il lessico tecnico delle plaidoiries nel Settecento («'L'unité de sujet' dans les plaidoiries du XVIII ${ }^{e}$ siècle. Voir depuis le même 'point de vue'», pp. 175-201), l'A. presenta il caso di un processo che il celebre avvocato Henri Cochin vinse, secondo le testimonianze dell'epoca, grazie all'uso sapiente dell'ironia («Une victoire scandaleuse, mais instructive. L'affaire Rapalli», pp. 203-222). Nei documenti analizzati si sottolinea la preminenza dell'argomentazione sulla narrazione dei fatti, un dato che emerge in maniera particolare nel caso dell'affaire Titius VS Séjus (tratto da una raccolta di arringhe e sentenze ispirate a processi reali pubblicata nel 1596), dove l'arringa vincente appare caratterizzata essenzialmente da una compositio più raffinata («Tête synthétique et souci systémique. Promesse et contre-promesse dans l'affaire Séjus», pp. 223-273). La terza parte del volume («Vers un autre paradigme constructif») si compone anch'essa di due casi di studio preceduti da un capitolo di carattere teorico («Voir les figures de pensée comme des loci. Une leçon d'anatomie», pp. 277-310). L'ipotesi formulata dall'A. è che, data la formazione retorica degli autori e dei lettori del xvi secolo, sia possibile considerare attraverso il prisma della dispositio anche opere che non sembrerebbero riconducibili al paradigma retorico classico, come i Regrets di Du Bellay e gli Essais di Montaigne. È a queste due opere che sono dedicati i capitoli conclusivi («Un exemple de lecture par loci. Les Regrets de Du Bellay», pp. 311-334; «Les Essais entre marqueterie 'mal jointe' et nid 'bien joint'», pp. 335-365), nei quali viene messa alla prova l'efficacia delle nozioni di locus (da intendersi come luogo testuale cui corrisponde una figura di pensiero), di collocatio (composizione dei luoghi testuali così definiti gli uni rispetto agli altri) e di iunctura per verificare la possibilità di ritrovare un ordine interno. 